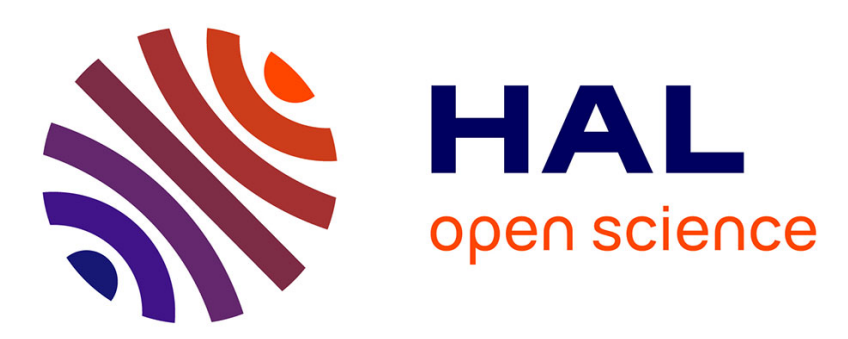

\title{
Fast and complete electrochemical conversion of solutes contained in micro-volume water droplets
}

\author{
Louis Godeffroy, François Chau, Olivier Buriez, Eric Labbé
}

\section{To cite this version:}

Louis Godeffroy, François Chau, Olivier Buriez, Eric Labbé. Fast and complete electrochemical conversion of solutes contained in micro-volume water droplets. Electrochemistry Communications, 2018, 86, pp.145 - 148. 10.1016/j.elecom.2017.12.007 . hal-01677367

\section{HAL Id: hal-01677367 \\ https://hal-ens.archives-ouvertes.fr/hal-01677367}

Submitted on 8 Jan 2018

HAL is a multi-disciplinary open access archive for the deposit and dissemination of scientific research documents, whether they are published or not. The documents may come from teaching and research institutions in France or abroad, or from public or private research centers.
L'archive ouverte pluridisciplinaire HAL, est destinée au dépôt et à la diffusion de documents scientifiques de niveau recherche, publiés ou non, émanant des établissements d'enseignement et de recherche français ou étrangers, des laboratoires publics ou privés. 


\section{Fast and Complete Electrochemical Conversion of Solutes contained in Micro-Volume Water Droplets.}

Louis Godeffroy ${ }^{1}$, François Chau ${ }^{2}$, Olivier Buriez ${ }^{1}$ and Eric Labbé ${ }^{*}$

${ }^{1}$ PASTEUR, Département de chimie, École Normale Supérieure, PSL Research University, Sorbonne Universités, UPMC Univ. Paris 06, CNRS, 75005 Paris, France.

${ }^{2}$ Univ Paris Diderot, Sorbonne Paris Cite, ITODYS, UMR 7086 CNRS, 15 rue J-A de Barf, 75205 Paris Cedex 13, France

* Corresponding author: eric.labbe@ens.fr

\section{ABSTRACT}

An elegant hanging-droplet or meniscus-based setup is proposed to carry out quantitative electrolyses from either an organic (hydroquinone) or an inorganic (permanganate) substrate. These examples validate the concept of using such easily-accessible, fast (1-3 $\mathrm{min}$ ) and low-cost operating conditions not only for preparative applications (electrosynthesis), but also for pedagogical purposes in minute samples.

\section{KEYWORDS}

Water droplets ; Electrochemical setup ; Complete electrolysis; Low cost; pedagogical application.

\section{HIGHLIGHTS}

- The simplest low cost electrochemical cell : Water droplets hanging at the tip of a glass frit are used as vessels to carry out 2-compartment electrolyses

- Complete electrochemical conversions can be achieved within a minute time window

- The methodology is adapted to occasional electrochemical investigation as well as electrochemical teaching.

- GRAPHICAL ABSTRACT

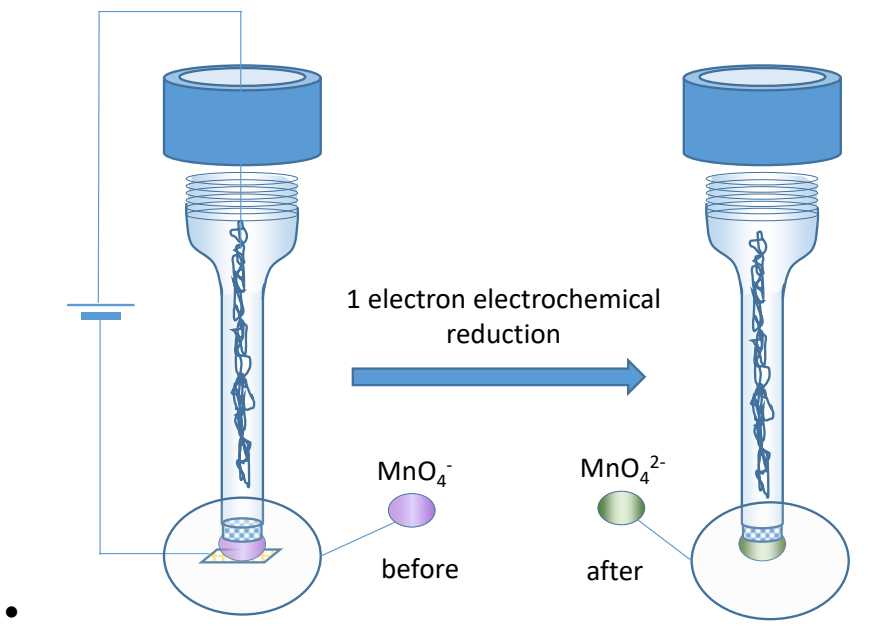




\section{Introduction}

The miniaturization of reaction vessels is a growing concern in modern preparative and analytical chemistry. Indeed, the obvious substrate economy realized upon downsizing volumes is associated to the development of flow reactors allowing fast, successive synthetic steps $[1,2]$ as well as multiple analyte determination in microfluidic analyzers $[3,4]$.

Besides, the quest for smaller reactors may also encompass a more prospective chemistry, viz. fundamental or applied research where inexpensive, accessible and disposable general-purpose setups would allow fast validation of experiments or concepts. The intrinsic complexity of electrochemical experiments (featuring at least two electrodes in continuity in the electrolyte), especially when it comes to electrosynthesis, generally implies specific glassware and cells which become even more complex and expensive for small volumes. We recently established the possibility to perform electrochemical experiments within the simplest and cheapest available reaction vessel, i.e. a hanging droplet [5]. The originality of this work relied on the fact that micro-volume droplets were not "deposited" on a substrate or at the electrode surface, but left suspended at the fritted glass of a bridge compartment containing a conventional reference electrode (SCE). The use of water droplets as electrochemical cells is not a new concept per se. In 1992, Mc Creery et al. deposited droplets on ordered carbon/graphite electrodes to study the dependence of electron transfer kinetics on the surface defects of such electrodes [6]. More recently, a similar droplet-based setup was used by Unwin either to explore the electron transfer kinetics on highly oriented pyrolytic graphite (HOPG) electrodes [7] or to perform Scanning Electrochemical Cell Microscopy (SECCM) on samples contained in droplets or meniscus [8]. A more comprehensive survey on "droplet electrochemistry" was published by Davies et al. who performed voltammetry and electrodeposition at edge plane pyrolytic graphite electrodes within droplets immersed in an immiscible organic electrolyte [9]. 
In our approach, where the droplet hang at the tip of a glass frit, the solution was not deposited on a plane surface or electrode, but featured an inverted cell configuration with respect to the above described setups. Such a device is designed both to minimize sample contamination (no other contact than the frit) and to allow electrochemistry to be performed without specific or printed working electrodes. Accordingly, both working and counter electrodes were introduced in the droplet, thus designing a classical 3-electrode setup in microliter-size volume featuring a commercial reference electrode instead of pseudo-reference wire-shape electrodes (e.g. $\mathrm{Ag}, \mathrm{Ag} / \mathrm{AgCl}, \mathrm{Pt}$ ). We showed that analytical electrochemistry (voltammetry) could be performed within the droplet, as well as short scale preparative electrochemistry with the examples of platinization and electrodeposition of gold nanocrystals onto carbon-fiber electrode surfaces. These results prompted us to go one step further in the achievement of electrolyses within a droplet by performing the complete electrochemical conversion of a solute dissolved in the droplet, therefore featuring a separator between the working and the counter electrodes in order to avoid generator-collector mode electrolysis. In this work, we have explored the possibility to carry out quantitative electrolyses on organic and inorganic species dissolved in water droplets. We notably considered the electrochemical oxidation of hydroquinone and the electrochemical reduction of permanganate in alkaline droplets. Actually, the oxidation of hydroquinone was selected as an example of electrosynthetic application achieved from controlled potential electrolyses using a 3-electrode setup while permanganate conversion in hanging droplets (galvanostatic 2-electrode setup) was proposed as an illustrative experimental entry to an electrochemistry teaching based on quantitative electrochemical transformations.

\section{Experimental section}

\section{$2.1 \quad$ Procedure}

The original electrochemical setup described in our previous paper [5], which only consisted in a vertical glass frit (porosity 4) has been completed by a second U-shaped glass frit to host the reference electrode. All glassware was purchased from Ellipse Labo, then cut or curved to the desired shape by 
a glassblower and then fitted with a thread to host a $15 \mathrm{~mm}$-diameter cap. The scheme and pictures of the corresponding setup are shown in Figure 1 for either a 2-electrode setup (hanging droplet) or a 3-electrode setup (meniscus placed between the two frits). Working electrode $\mathbf{2}$ was a gold square grid ( $5 \mathrm{~mm} \times 5 \mathrm{~mm}$ ) and the counter electrode, placed in compartment 3, was a stainless steel grid. Compartments $\mathbf{3}$ and $\mathbf{4}$ were carefully filled with the same electrolytes than those of the droplets using $5 \mathrm{~mL}$ plastic syringes equipped with needles in order to avoid air bubbles to form in the vicinity of the frit. Once the compartments were filled with electrolyte, a 50 or $75 \mu \mathrm{L}$ droplet was placed at the bottom of compartment 3 using an Eppendorf pipette fitted with a $200 \mu \mathrm{L}$ plastic tip. For 3 -electrode electrolyses, the U-shaped compartment 4 was lifted up towards the hanging droplet until it finally formed a meniscus 1, the original droplet being immobilized between compartments $\mathbf{3}$ and $\mathbf{4}$ (see Figure 1 for a detailed view). The electrochemical monitoring of hydroquinone and benzoquinone concentrations along the electrolysis was carried out by cyclic voltammetry at a homemade Pt disk microelectrode (100 $\mu \mathrm{m}$ diameter, see right photograph in Fig 1) introduced in the droplet. In both potentiostatic and galvanostatic mode electrolyses using potassium chloride $0.1 \mathrm{~mol} . \mathrm{L}^{-1}$ or sodium hydroxide 1 mol.L-1 as electrolytes, the potential difference between the working (gold grid) and counter (stainless steel) electrodes was in a 4 to $6 \mathrm{~V}$ window (current range 1-5 $\mathrm{mA}$ ), mostly accounting for the resistance introduced by the glass frit separator. Nevertheless, this potential difference allow galvanostatic electrolyses to be performed with unspecific apparatus, such as a simple power supply instead of a potentiostat.

\subsection{Chemicals}

For the hydroquinone oxidation experiments, the electrolyte consisted of a $0.1 \mathrm{~mol}^{-1} \mathrm{~L}^{-1}$ solution of potassium chloride (Sigma Aldrich, $>$ 99\%) in deionized water, while permanganate reduction was achieved in 1 mol.L $\mathrm{L}^{-1}$ sodium hydroxide (Acros organics, $>98.5 \%$ ) in deionized water. Hydroquinone (HQ) was purchased from VWR chemicals and freshly recrystallized in deionized water. Benzoquinone 
(BQ) was purchased from Sigma Aldrich and recrystallized from petroleum ether. Potassium permanganate was purchased from VWR chemicals (> 99\%).

\subsection{Instrumentation}

All electrolyses and cyclic voltammetry were performed at room temperature using an Autolab potentiostat (PGSTAT 20). UV-Vis spectra were recorded on a Perkin Elmer Lambda 45 spectrophotometer.

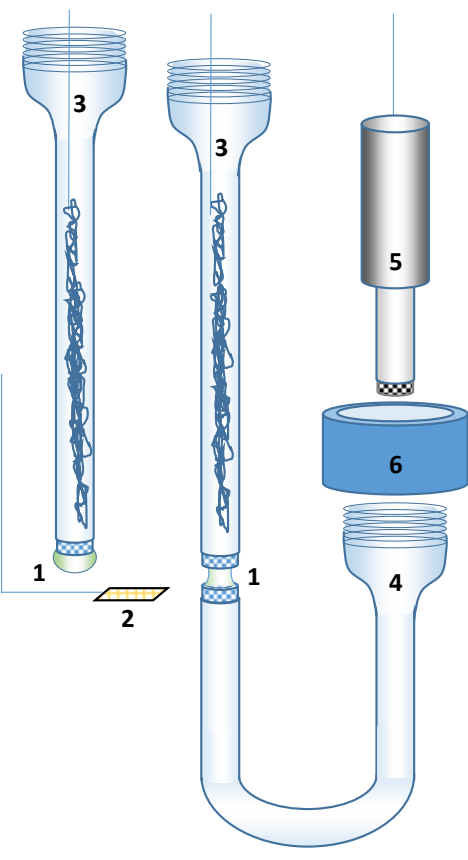

1. Solution of interest (50 or $75 \mu \mathrm{L}$ hanging droplet or meniscus).

2. Gold grid (Working electrode).

3. Counter electrode compartment.

4. Reference electrode compartment.

5. Saturated calomel electrode (SCE)

6. Cap
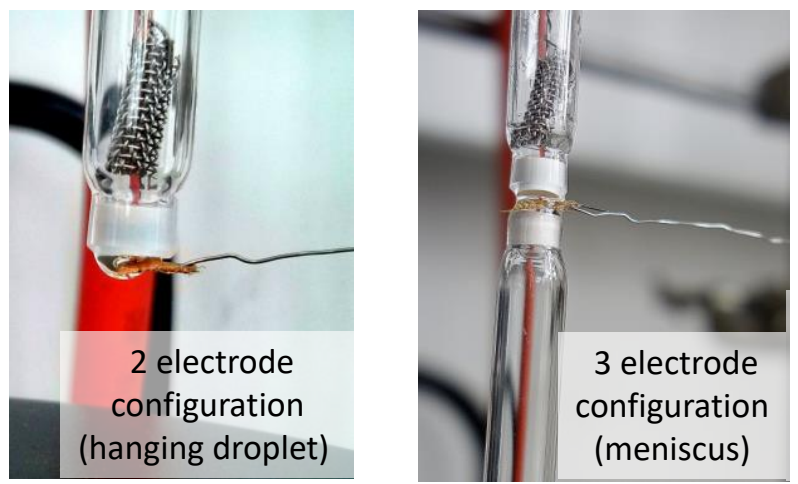

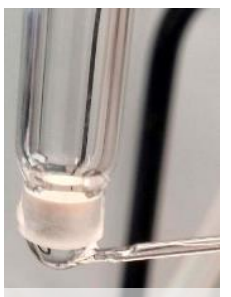

Pt microelectrode introduced in the droplet

Figure 1

Scheme and photographs of the setup used in this work

\section{Results and discussion}

\subsection{Electrochemical conversion of hydroquinone (HQ) to 1,4-benzoquinone (BQ)}

Hydroquinones are ubiquitous compounds which namely enable electron transfer along the photosynthetic chain [10], are used as precursors in the synthesis of quinones [11] or prevent radical polymerization of vinyl monomers [12]. On the other hand, hydroquinones are toxic [13] and their content in wastewater is scrutinized [14, 15]. Therefore, the conversion of hydroquinone (benzene- 
1,4-diol, HQ) appeared as a meaningful example to estimate the efficiency of an electrochemical oxidation carried out from a droplet containing this organic water-soluble molecule. The controlled potential electrolysis of $\mathbf{H Q}$ to benzoquinone (BQ) was achieved in only $60 \mathrm{~s}$ in an aqueous droplet solution of potassium chloride $\left(0.1 \mathrm{~mol}^{-1} \mathrm{~L}^{-1}\right)$ using the 3 -electrode setup. The oxidation potential was set at $1.7 \mathrm{~V} / \mathrm{SCE}$, i.e. the more positive value to ensure fast electron transfer without significant $\mathrm{O}_{2}$ or $\mathrm{Cl}_{2}$ evolution at the gold electrode. Note that under these conditions, as verified in our previous work [5] no water evaporation was observed from the droplet. In Figure 2, The conversion of HQ and formation of BQ were monitored by in situ cyclic voltammetry using a $100 \mu \mathrm{m}$ Pt microelectrode (the electrolysis was stopped while recording the cyclic voltammograms (CVs)) as shown in Figure 2A and $2 \mathrm{~B}$, respectively. Under our conditions (unbuffered aqueous solution), HQ oxidation peak originally at $0.52 \mathrm{~V} / \mathrm{SCE}$ shifted towards more positive potentials values while electrolysis proceeded.
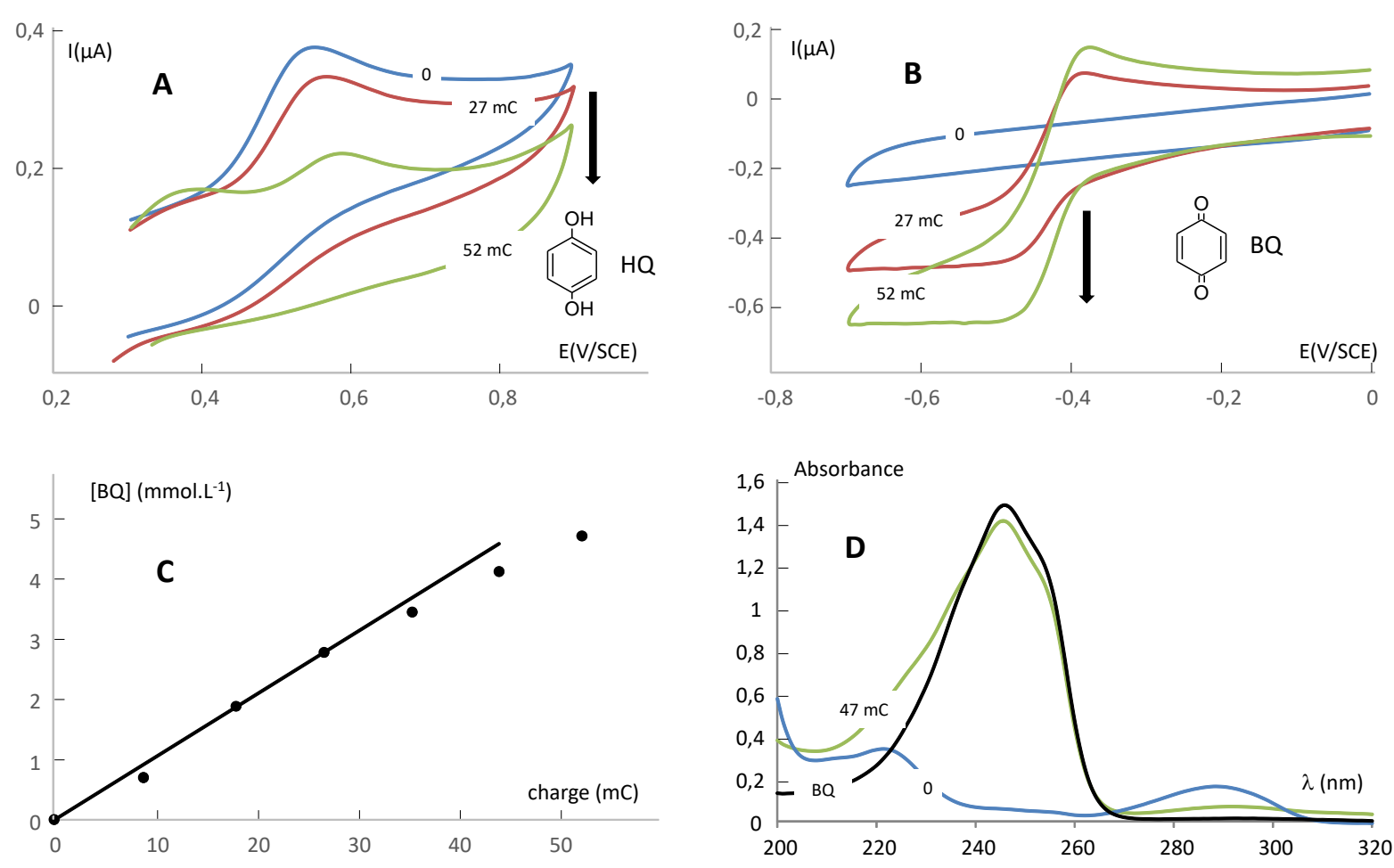

Figure 2

Electrochemical oxidation of hydroquinone $\mathrm{HQ}\left(5 \mathrm{mmol} . \mathrm{L}^{-1}\right.$ contained in a $50 \mu \mathrm{L}$ aqueous $0.1 \mathrm{~mol} . \mathrm{L}^{-1}$ $\mathrm{KCl}$ droplet) at $1.7 \mathrm{~V}$ vs. SCE using the 3-electrode configuration. A : Evolution of the CVs of $\mathbf{H Q}$ as a function of the charge (scan rate $0.2 \mathrm{~V} \cdot \mathrm{s}^{-1}$ ). B : Evolution of the CVs of BQ as a function of the charge (scan rate 0.2 V.s $\mathrm{s}^{-1}$ ). C : Experimental (points) and theoretical (for $100 \%$ faradaic efficiency, solid line) concentration of $\mathbf{B Q}$ formed as a function of charge - experimental concentration estimated from the calibration of the plateau reduction currents of $\mathbf{B Q}$ (like in panel B) with an authentic sample of BQ (5 mmol. $\left.\mathrm{L}^{-1}\right)$. D: UV-vis spectra of HQ (5 $\mathrm{mM}$ ) before (blue curve) and after (green curve) electrolysis of 
the droplet $(47 \mathrm{mC})$. The black curve is the UV-vis spectra of an authentic BQ sample performed at a concentration ( $5 \mathrm{mM}$ ) corresponding to a $100 \%$ conversion of $\mathrm{HQ}$.

The complex electrochemistry of the hydroquinone/quinone redox couple is well documented $[16,17]$, even in unbuffered solutions [18] but mechanistic considerations related to the $\mathrm{pH}$ dependence of hydroquinone electrooxidation were out of the scope of this work. Actually, HQ oxidation did not provide a linear relationship between the peak current and HQ concentration, while BQ displayed a stable and linear plateau-shaped reduction wave at $-0.48 \mathrm{~V} / \mathrm{SCE}$ which allowed its concentration to be monitored by cyclic voltammetry (Figure $2 \mathrm{~B}$ and $2 \mathrm{C}$ ). The nearly quantitative conversion of $\mathbf{H Q}$ to $\mathbf{B Q}$ during electrolysis was assessed by the overlay of experimental and expected faradaic formation of $\mathbf{B Q}$ (Figure 2C) and by the UV-vis spectra recorded before and after electrolysis (Figure 2D). This confirms that no secondary electrode reactions (like oxygen evolution) were not observed in our conditions. Besides, comparison between the UV-vis spectra obtained after electrolysis and the one recorded for an authentic BQ sample at a concentration of $5 \mathrm{mM}$ (i.e, the same concentration used for the starting HQ) confirmed the full conversion of HQ into BQ (Figure 2D). Moreover, even if HQ did not exhibit a stable oxidation peak in our conditions, the evolution of the CVs in Figure $1 \mathrm{~A}$ were consistent with the conversion of $\mathbf{H Q}$.

\subsection{Electrochemical reduction of permanganate in alkaline aqueous solutions}

The objective of this work was also to test a qualitative and visual electrochemical transformation that could be performed in water droplets. Actually, manganese high oxidation states are very interesting with this respect, especially in alkaline media where permanganate $\mathrm{MnO}_{4}^{-}$(purple), manganate $\mathrm{MnO}_{4}{ }^{2-}$ (green) and even hypomanganate $\mathrm{MnO}_{4}{ }^{3-}$ (grey-blue) ions can be formed. Such transformations are currently realized by undergraduate students in test tubes [19] and the corresponding oxidation states described structurally and thermodynamically $[20,21]$. Since i) the standard potential values of the $\mathrm{MnO}_{4}{ }^{-} / \mathrm{MnO}_{4}{ }^{2-}$ and $\mathrm{MnO}_{4}{ }^{2-} / \mathrm{MnO}_{4}{ }^{3-}$ in alkaline solutions $(0.558 \mathrm{~V} / \mathrm{SHE}$ and $0.285 \mathrm{~V} / \mathrm{SHE}$ respectively [22]) establish the thermodynamic stability of the intermediate oxidation state and ii) the electrochemical successive generation of $\mathrm{MnO}_{4}{ }^{2-}$ and $\mathrm{MnO}_{4}{ }^{3-}$ from $\mathrm{MnO}_{4}{ }^{-}$has been described the

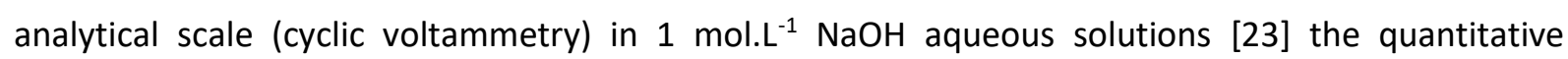
electrochemical generation of $\mathrm{Mn}(\mathrm{VI})$ and $\mathrm{Mn}(\mathrm{V})$ anions from an alkaline permanganate droplet could be successful. In order to make the electrolysis as simple as possible, we used the 2-electrode setup with the hanging droplet under galvanostatic conditions (no reference electrode connected). The results of the one- and two-electron reduction of a $10^{-2}$ mol. $\mathrm{L}^{-1}$ potassium permanganate droplet in aqueous 1 mol.L-1 sodium hydroxide solution are presented in Figure 3.The color evolution could not 
be directly observed during electrolysis (under conventional lighting the droplet was too dark), but was very apparent once the droplet diluted (Figure 3A). Both the color and the UV-vis spectrum (maximum absorption at $620 \mathrm{~nm}$, in agreement with literature [24]) clearly indicated a rather quantitative $1 \mathrm{~F} / \mathrm{mol}$ conversion of permanganate according to $\mathrm{MnO}_{4}{ }^{-}+\mathrm{e}^{-} \rightarrow \mathrm{MnO}_{4}{ }^{2-}$. Upon continuing the electrochemical reduction to a final $2 \mathrm{~F} / \mathrm{mol}$ relative charge vs. initial permanganate, the green intermediate solution became light blue, slowly turning to blue-grey. The UV-vis spectrum at $2 \mathrm{~F} / \mathrm{mol}$, recorded 2 minutes after the end of the electrolysis (blue line in Figure 3B), did not exhibit the expected maximum at 670 $\mathrm{nm}$ for $\mathrm{MnO}_{4}{ }^{3-}$ [22], but displayed most of the characteristics of permanganate absorption (compare with the purple curve in Figure 3B). Actually, and as already reported [19], this color change is consistent with the instability of the hypomanganate ion in the presence of oxygen (our experiments were performed under aerobic conditions) as well as its synproportionation according to $\mathrm{MnO}_{4}^{-}+$ $\mathrm{MnO}_{4}{ }^{3-} \rightarrow 2 \mathrm{MnO}_{4}{ }^{2-}$.
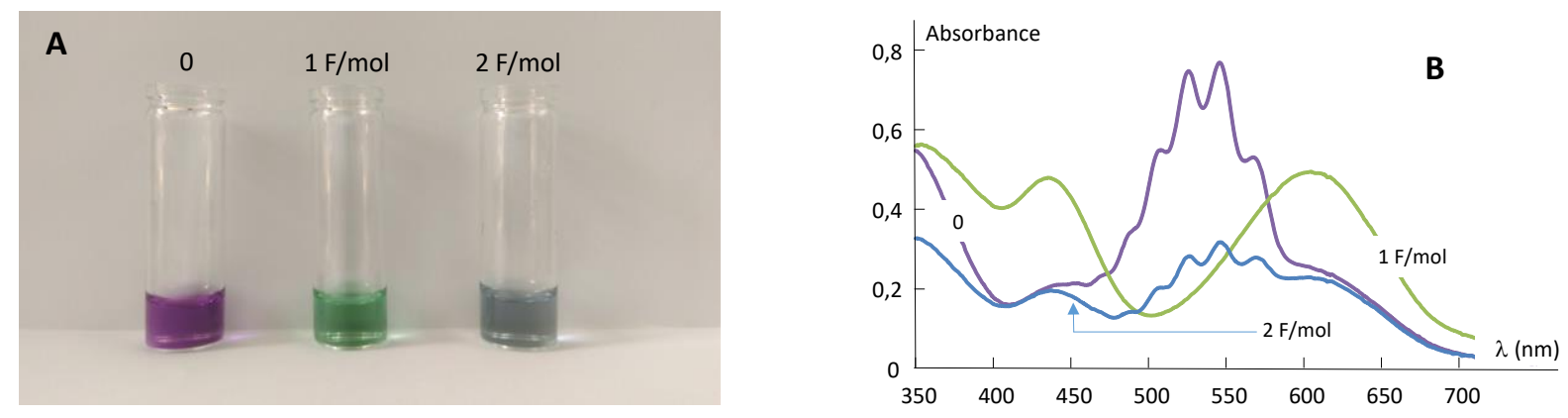

Figure 3

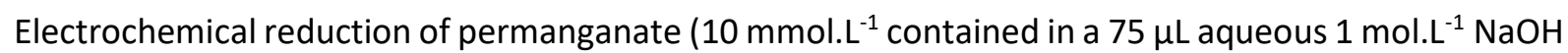
droplet) at $1 \mathrm{~mA}$ using the 2 electrode configuration. A: Photographs of the $75 \mu \mathrm{L}$ droplet diluted in 1 $\mathrm{mL}$ deionized water before electrolysis (0), after $75 \mathrm{mC}(1 \mathrm{~F} / \mathrm{mol})$ and $150 \mathrm{mC}(2 \mathrm{~F} / \mathrm{mol})$. B: UV-vis absorption spectra of the same diluted droplets recorded $2 \mathrm{~min}$ after the electrolyses.

\section{Conclusion}

One of the simplest and smallest setup allowed the achievement of fast and complete electrochemical conversions, from examples taken among organic substrates or inorganic species. Electrochemical preparations in droplets from the same setup should also be accessible in organic solvents, upon confinement within a chamber allowing saturated solvent vapor pressure, as described for analytical applications [5]. The possibility to carry out either controlled-potential electrolyses (3 electrodes) or galvanostatic ones (2 electrodes) make such a fast, low-amount / low cost electrochemistry available and attractive for novice or occasional operators as well as for teachers looking for simple electrochemical experiments. 


\section{Acknowledgements}

This work was supported by the CNRS (UMR 8640), the Ecole Normale Supérieure, Université P. et M. Curie, and Université Paris Diderot.

\section{References}

[1] J.C. Pastre, D.L. Browne, S.V. Ley, Flow chemistry syntheses of natural products, Chemical Society Reviews, 42 (2013) 8849-8869.

[2] I.R. Baxendale, C.M. Griffiths-Jones, S.V. Ley, G.K. Tranmer, Microwave-assisted Suzuki coupling reactions with an encapsulated palladium catalyst for batch and continuous-flow transformations, Chemistry-a European Journal, 12 (2006) 4407-4416.

[3] W.R. Melchert, B.F. Reis, F.R.P. Rocha, Green chemistry and the evolution of flow analysis. A review, Analytica Chimica Acta, 714 (2012) 8-19.

[4] A.M. Leach, A.R. Wheeler, R.N. Zare, Flow injection analysis in a microfluidic format, Analytical Chemistry, 75 (2003) 967-972.

[5] A.I.P. Jimenez, L. Challier, M. Di Pisa, M. Guille-Collignon, F. Lemaître, S. Lavielle, C. Mansuy, C. Amatore, E. Labbé, O. Buriez, Three-electrode analytical and preparative electrochemistry in microvolume hanging droplets, Electrochemistry Communications, 54 (2015) 41-45.

[6] M.T. McDermott, K. Kneten, R.L. McCreery, Anthraquinonedisulfonate adsorption, electrontransfer kinetics, and capacitance on ordered graphite-electrodes - the important role of surfacedefects, Journal of Physical Chemistry, 96 (1992) 3124-3130.

[7] G. Zhang, A.S. Cuharuc, A.G. Gueell, P.R. Unwin, Electrochemistry at highly oriented pyrolytic graphite (HOPG): lower limit for the kinetics of outer-sphere redox processes and general implications for electron transfer models, Physical Chemistry Chemical Physics, 17 (2015) 1182711838.

[8] N. Ebejer, A.G. Güell, S.C.S. Lai, K. McKelvey, M.E. Snowden, P.R. Unwin, Scanning Electrochemical Cell Microscopy: A Versatile Technique for Nanoscale Electrochemistry and Functional Imaging, Annual Review of Analytical Chemistry, 6 (2013) 329-351.

[9] T.J. Davies, S.J. Wilkins, R.G. Compton, The electrochemistry of redox systems within immobilised water droplets, Journal of Electroanalytical Chemistry, 586 (2006) 260-275.

[10] B. Schoepp-Cothenet, R. van Lis, A. Atteia, F. Baymann, L. Capowiez, A.-L. Ducluzeau, S. Duval, F. ten Brink, M.J. Russell, W. Nitschke, On the universal core of bioenergetics, Biochimica et Biophysica Acta (BBA) - Bioenergetics, 1827 (2013) 79-93.

[11] R.J. Radel, J.M. Sullivan, J.D. Hatfield, Catalytic oxidation of hydroquinone to quinone using molecular oxygen, Industrial \& Engineering Chemistry Product Research and Development, 21 (1982) 566-570.

[12] H. Becker, H. Vogel, The role of hydroquinone monomethyl ether in the stabilization of acrylic acid, Chemical Engineering \& Technology, 29 (2006) 1227-1231.

[13] A.L. Buikema, M.J. McGinniss, J. Cairns, Phenolics in aquatic ecosystems - selected review of recent literature, Marine Environmental Research, 2 (1979) 87-181.

[14] J.S. Hu, J.L. Dong, Y. Wang, L. Guan, Y.Y. Duan, Hydroquinone Wastewater Treatment by Means of Electrochemical Oxidation in Three-dimensional Bipolar Cell, Advances in Environmental Science and Engineering, Pts 1-6, 518-523 (2012) 2539-2542.

[15] N.S. Arul, D. Mangalaraj, J.I. Han, L.S. Cavalcante, Structure and electrochemical detection of xenobiotic micro-pollutant hydroquinone using CeO2 nanocrystals, Rsc Advances, 5 (2015) 7055870565. 
[16] J.Q. Chambers, Electrochemistry of quinones, in: S. Patai (Ed.) Quinonoid compounds : volume 2, vol. 2, John Wiley \& Sons, Ltd., Chichester, UK., 1974, pp. 737--791.

[17] E. Laviron, Electrochemical reactions with protonations at equilibrium .13. Experimental-study of the homogeneous electron exchange in quinone dihydroquinone systems, Journal of Electroanalytical Chemistry, 208 (1986) 357-372.

[18] M. Quan, D. Sanchez, M.F. Wasylkiw, D.K. Smith, Voltammetry of Quinones in Unbuffered Aqueous Solution: Reassessing the Roles of Proton Transfer and Hydrogen Bonding in the Aqueous Electrochemistry of Quinones, Journal of the American Chemical Society, 129 (2007) 12847-12856. [19] P. Ruoff, The stepwise reduction of permanganate in alkaline conditions : A lecture demonstration, Journal of Chemical Education, 64 (1987) 624.

[20] B.E. Douglas, D.H. McDaniel, J.J. Alexander, Concepts and Models of Inorganic Chemistry, 3rd Edition, Wiley, 1994.

[21] A.F. Cotton, G. Wilkinson, C.A. Murillo, B. Manfred, Advanced Inorganic Chemistry, 6th Edition, Wiley-Interscience, New York, 1999.

[22] A. Carrington, M.C.R. Symons, Structure and reactivity of the oxy-anions of transition metals .1. The manganese oxy-anions, Journal of the Chemical Society, (1956) 3373-3380.

[23] D.B. Freeman, G. Mamantov, Linear sweep voltammetry of manganate(vii), manganate(vi), and manganate(v) in alkaline media, Electrochimica Acta, 21 (1976) 257-261.

[24] J.T. Wrobleski, G.J. Long, Electronic spectra of tetrahedral $\left[\mathrm{MnO}_{4}\right]^{\mathrm{m}-}$ chromophore, Journal of Chemical Education, 54 (1977) 75-79. 